\title{
Nataša Petrović
}

University of Belgrade, Faculty of Organizational Sciences, Serbia

\section{BOOK REVIEW}

DOI: 10.7595/management.fon.2020.0005

\begin{abstract}
:
Book review of: Strategic Management and the Circular Economy by Marcello Tonelli and Nicoló Cristoni. New York: Routledge, 2019. | Series: Routledge research in strategic management. 235pp ISBN 9781138103634 (hardback), ISBN 9781315102641 (e-book)
\end{abstract}

\section{JEL Classification: Q01}

The beginning of the review of this book that came out in a year that ended with the signs of the coming tremendous, (un)expected and sadly dire consequences of the global, potentially catastrophic, pandemic of the coronavirus (COVID - 19), which already consumed two quarters of 2020 all around the world (affecting not only the public health of the entire Planet, already showing its economic, social, environmental and cultural effects, hence its impacts on the sustainable development pillars) should certainly start with the authors' opening of the book where they state that they are "dedicated to our awareness of interconnectedness and the hope for a better future", as well as with the following quote by the authors': "Without hope, I fear that life loses much of its purpose and actions become meaningless. So, if the distinctive knowledge of our time - which sets us apart from previous millennia of human history - is based on the certainty of anthropogenic activities irreversibly damaging the Earth's ecosystems at an uncontrolled pace and on the dreadful consequences of this new reality for any living organism, we also need to have hope (i.e., a belief system, faith, etc.) based on something equally tangible and 'real'". This is especially suitable because this book is about Circular Economy (CE) which aims to meet the challenges set before all societies and individuals who are unfortunately continually facing a plethora of environmental problems, contradictions, risks and uncertainties associated with future challenges of global sustainable development, where the only possible way to address them is through appropriate measures for environmental protection and development of global sustainability, which may include, first and foremost, sustainable management of natural renewable and non-renewable resources and an efficient use of energy. All of the above should be understood as a precondition for fulfilling the requirement and enabling the creation of goods needed for securing and improving social and economic well-being while preserving the environmental capital of the planet if we have invested interest in preventing, as Amin Maalouf notes so well: creating an unsustainable state that can result in potentially irreversible threats to human societies. Since the last industrial revolution, economy has been viewed as a process that involves the extraction of available natural resources through a linear model of the economy in which the main paradigm is take - make/use - dispose, which in addition to the ruthless exploitation of natural resources, increases the amount of generated waste enormously.

Such linear economy has put humanity at the forefront of the following global threats and their implications:

- Climate changes and the consequent inability to meet basic human needs with rising commodity prices.

- Excessive consumption of non-renewable energy sources, primarily energy, leading to inflation, economic imbalance and stalled economic development, depending on raw material supply, and rising prices of goods and services.

- Excessive population growth leading to an increase in the price of land and basic goods, as well as an inability to meet the basic needs of people (water and food). 
On the other side of this model is the biosphere - the oldest global "enterprise" on the planet that has been operating for over 3 billion years and successfully secures its survival. The production part of this system, made up of an infinite number of plants and small algae, processes about 200 billion tons of carbon annually into organic matter, producing about 100 billion tons of oxygen and $8 \times 10 \mathrm{kWh}$ of energy.

In full analogy with natural systems, economics should start with natural raw materials and continue with processing them into products. The products then go into the use phase, after which they become waste (recyclable) and reused as raw material. Such production systems are ecological systems type III, that is, closed-loop type in which all materials are included in the roundabouts, and such systems are the basis of the idea of CE, because human enterprise, as the authors state: "can no longer rely on its traditional economic paradigm and the latter presenting the solid rationale behind what has been framed as an alternative system that "opens up ways to reconcile the outlook for growth and economic participation with that of environmental prudence and equity'".

Bearing in mind the above, the authors, on 235 pages covering all major topics of Strategic Management and CE, through four sections (An Overview, Circular Economy Strategy, CE Strategic Management and CE @ $360^{\circ}$ ) and 13 chapters (plus Index of used specific terms from the authors) focused on the following: The Challenges of the Produce-Use-Dispose Model; An Introduction to the Circular Economy; A CE Framework for Action; CE-Enabling Technologies; Business Models for a CE; Introducing the CE Strategic Process; CE Data Collection and Prioritization: Firm, Industry, and External Levels of Analysis; CE Data Integration; Determining Your Preferred CE Position; Gap Analysis, CE Strategy Formulation, and Planning; Tools for CE Analysis at a Micro Level; Tools for a CE Analysis at a Macro Level; Conclusions.

In their book, the authors showed a remarkable review of the most important elements of Strategic Management and CE shown through a series of examples regarding: Exceeding Planetary Natural Thresholds; Scarcity of Raw Materials and Price Volatility; Rising Middle-Class Population; Structural Inefficiencies of the Current Economic Model; Biosphere and Technosphere Products; Technological, Regulatory, and Social Factors; EMS vs CE; CE Guiding Principles; CE Business Objectives; CE Areas of Intervention; Digital Technologies; Design and Engineering Technologies; Net-Zero Innovation; Servitization; Product Life Extension; Product Residual Value Recovery; Organizational Culture; The CE Strategic Process; Current Strategy Identification; Idea Trees; The VRIE Framework; Five Forces, PEST Analysis; Supporting Methods for Undertaking PEST Analysis: Interviewing Key Personnel; PEST vs Five Forces Matrix; SWOT Analysis; Strategic Quadrant; Approaches to Internationalization; Gap Analysis; Formulating a CE Strategy; CE Strategic Planning; Life Cycle Assessment (LCA); Life Cycle Costing (LCC); Material Input per Unit of Service (MIPS); Material Flow Analysis (MFA); Value Chain Analysis (VCA); Environmental Input-Output Analysis (EIOA); Ecological Footprint (EF); Environmentally weighted Material Consumption (EMC); Land and Ecosystem Accounts (LEAC); Human Appropriation of Net Primary Production (HANPP); Environmental Impact Assessment (EIA) and Strategic Environmental Assessment (SEA); Cost-Benefit Analysis (CBA) and Cost Effectiveness Analysis (CEA).

Finally, perhaps the most interesting part of the book refers to the Net-Zero Innovation as a brand-new business model, that significantly differs from the traditional business models where the companies value only the increase of profits and salaries above all, not taking care of their products after they have been sold. As the authors state, the CE "progressively moved from theory to practice; hence, this also implies new business models that should ensure sustainable and responsible business operations that primarily highlight and implement proactive environmental practices. One such model is Net-Zero Innovation, which means "environmentally friendly production processes, with inputs and final products carrying a negligible or no environmental footprint, if a net positive impact on the environment is not achievable." It should be noted that the Ecological Footprint (EF) methodology refers to the determination of a measure that represents the needs of the human biosphere (bioavailable land and water resources) and, on the other hand, the ability of the planet's ecosystem to absorb the waste that humanity generates.

Last but not least, after reading this book, every one of its readers can believe that there is still hope for humanity and, as the authors Tonelli and Cristoni quote Victor Hugo's eponymous quote: "you can resist an invading army; you cannot resist an idea whose time has come" because the time has come for Circular Economy that reflects a good and humane relationship with planet Earth. 


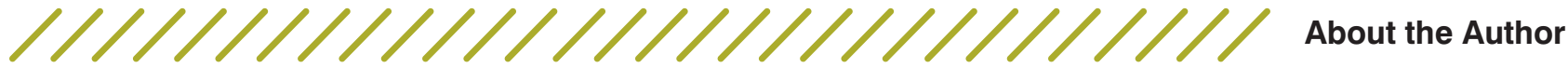

\section{Nataša Petrović}

Faculty of Organizational Sciences, University of Belgrade, Serbia E-mail: natasa.petrovic@fon.bg.ac.rs

Dr Nataša B. Petrović is a Full Professor at the University of Belgrade - Faculty of Organizational Sciences, Serbia, where she acquired her M.Sc. (1999) and Ph.D. (2002) degrees in Environmental management. She is the founder and head of the Centre for Environmental Management and Sustainable Development. The areas of her research include: Environmental Management, Sustainable Development, Green Marketing, Environmental Education and Education for Sustainable Development, Environmental Risk Management, Sustainable Energy Management, Circular Economy. 